\title{
Identification and characterization of LIM gene family in Brassica rapa
}

Jong-In Park ${ }^{1 \dagger}$, Nasar Uddin Ahmed ${ }^{1 \dagger}$, Hee-Jeong Jung ${ }^{1}$, Senthil Kumar Thamil Arasan, Mi-Young Chung ${ }^{2}$, Yong-Gu Cho ${ }^{3}$, Masao Watanabe ${ }^{4}$ and III-Sup Nou ${ }^{1 *}$

\begin{abstract}
Background: LIM (Lin-11, Isl-1 and Mec-3 domains) genes have been reported to trigger the formation of actin bundles, a major higher-order cytoskeletal assembly, in higher plants; however, the stress resistance related functions of these genes are still not well known. In this study, we collected 22 LIM genes designated as Brassica rapa LIM (BrLIM) from the Brassica database, analyzed the sequences, compared them with LIM genes of other plants and analyzed their expression after applying biotic and abiotic stresses in Chinese cabbage.

Results: Upon sequence analysis these genes were confirmed as LIM genes and found to have a high degree of homology with LIM genes of other species. These genes showed distinct clusters when compared to other recognized LIM proteins upon phylogenetic analysis. Additionally, organ specific expression of these genes was observed in Chinese cabbage plants, with BrPLIM2a, b, c, BrDAR1, BrPLIM2e, $f$ and $g$ only being expressed in flower buds. Furthermore, the expression of these genes (except for BrDAR1 and BrPLIM2e) was high in the early flowering stages. The remaining genes were expressed in almost all organs tested. All BrDAR genes showed higher expression in flower buds compared to other organs. These organ specific expressions were clearly correlated with the phylogenetic grouping. In addition, BrWLIM2C and BrDAR4 responded to Fusarium oxysporum f. sp. conglutinans infection, while commonly two BrDARs and eight BrLIMs responded to cold, $\mathrm{ABA}$ and $\mathrm{pH}(\mathrm{pH} 5, \mathrm{pH} 7$ and $\mathrm{pH} 9)$ stress treatments in Chinese cabbage plants.
\end{abstract}

Conclusion: Taken together, the results of this study indicate that BrLIM and BrDAR genes may be involved in resistance against biotic and abiotic stresses in Brassica.

Keywords: Brassica rapa, Characterization, Expression analysis, LIM gene, Stress resistance

\section{Background}

LIM proteins have mainly been described in animals in which they play key roles in a variety of important developmental processes $[1,2]$. These proteins contain one or several (up to five) double zinc finger motifs, known as LIM domains, which function by mediating proteinprotein interactions [3,4]. The three transcription factors, LIN11 from Caenorhabditis elegans [5], ISL-1 from rat [6] and MEC-3 from C. elegans [7], from which the acronym LIM is derived, operate during transcription in association with a DNA-binding homeodomain. LIM domains have since been found in a wide variety of

\footnotetext{
*Correspondence: nis@sunchon.ac.kr

'Equal contributors

'Department of Horticulture, Sunchon National University, 255 Jungangno,

Suncheon, Jeonnam 540-950, Republic of Korea

Full list of author information is available at the end of the article
}

eukaryotic proteins of diverse functions. LIM domaincontaining transcription factors without the homeodomain have also been described. Specifically, the LIM-only protein LMO2 was found to act as a bridging molecule in assembly of the erythroid DNA-binding complex [8], while other LIM-domain-containing proteins such as LIM kinases are known to participate in regulation of actin dynamics through phosphorylation of cofilin $[9,10]$. In contrast, plants possess two distinct sets of LIM proteins, one that is plant-specific and has been partially functional characterized [11,12]. Another, cysteine rich protein (CRP)-like that comprises CRPs exhibiting the same overall structure found in animals (i.e., two very similar LIM domains separated by an $\approx 50$ amino acid-long interLIM domain and a relatively short and variable $\mathrm{C}$-terminal domain) [13]. 
Plants have evolved mechanisms to exploit, survive, or minimize the negative impact of a diverse range of environmental factors including potential pathogens, and in many cases the plant cytoskeleton is instrumental in mediating the plant's response. Changes in organization of the plant cytoskeleton during plant interactions with these factors are complex and varied, and much still remains to be elucidated, especially in terms of the molecules that signal and induce the dramatic reorganizations that are often observed. Physical and chemical barriers resulting from actin-dependent cytoplasmic aggregation, secretion, and papilla formation appear to constitute an important and probably ancient form of basal resistance to pathogen attack [14]. Reorganization of cytoskeletal elements may also be a mechanism responsible for abiotic stress responses. For example, cytoskeletal elements translocate chloroplasts under high light conditions [15], facilitate gravity sensing [16], and direct cellular response to wounding $[17,18]$. A full understanding of the cytoskeletal basis of cytoplasmic aggregation will require identification and characterization of proteins involved in the signaling pathways those induce cytoskeletal rearrangement and responsible proteins for bringing about cytoskeletal reorganization and their function. This mechanism utilizes regulatory proteins that generate intracellular motility, such as myosin [19] and thick microfilament bundles focusing on the site of infection, such as the actin-bundling proteins villin and fimbrin $[20,21]$.

In the cytoplasm, actin monomers polymerize into actin filaments (AFs), which constitute the core elements of the actin cytoskeleton, providing mechanical support to the cytoplasm and serving as tracks for myosindependent intracellular transport [22,23]. To fulfill its various roles, the actin cytoskeleton requires a sophisticated regulatory system to control its organization and dynamics at both spatial and temporal levels. Primary components of this system are the actin binding proteins (ABPs) that directly interact with monomeric and/or polymerized actin to promote AF nucleation, polymerization, depolymerization, stabilization, severing, capping, and cross-linking [24]. Recently, a number of vertebrate LIM domain proteins belonging to the Cys-rich protein (CRP) family and several structurally related plant proteins (hereafter referred to as plant LIMs) have been shown to function as ABPs [25-28]. In Arabidopsis, two distinct LIM gene subfamilies have been reported. The first subfamily contains six genes, which encode proteins with two LIM domains that share similarity with animal CRPs [29]. These LIM domain-containing proteins bind actin filaments and influence actin cytoskeleton organization [29]. In vitro, chicken CRP1 and tobacco (Nicotiana tabacum) WLIM1 bind directly to AFs to trigger the formation of thick actin bundles. Importantly, over-expression of CRP1 and WLIM1 proteins has been shown to be sufficient to significantly increase the bundling of AFs in rat fibroblasts and tobacco cells, respectively $[13,26,27]$. The genes in the second subfamily encode DA1 and DA1 related (DAR) proteins with a single LIM domain and are specific to plants [11]. DA1 encodes a putative ubiquitin receptor with two ubiquitin interacting motifs (UIMs) and a single LIM domain, while e.g. DAR2 contains a single LIM domain and a putative zinc-binding domain but lacks UIMs suggesting a possible functional divergence with DA1 [30]. The members of this family are involved in diverse functions e.g. seed and organ size control, root meristem size control, resistance signaling and cold response [11,30,31].

In this study, we retrieved 22 Brassica rapa LIM genes from the Brassica database, analyzed the sequences and studied their homology with LIM genes of other species. We also analyzed their phylogenetic classification and discussed their correlation with organ specific expression. Expression of these genes was also analyzed following application of different biotic and abiotic stresses and their association was discussed with biotic and abiotic stress resistance in Brassica.

\section{Results and discussion}

\section{Sequence analysis and phylogenetic classification}

We identified 22 LIM proteins, designated as $B$ rapa LIM (BrLIM), after which the sequences were analyzed (Table 1). The predicted size of the 22 BrLIMs ranged from 92 to 1315 amino acids (10.36 to $150.61 \mathrm{kDa}$ ), and the predicted isoelectric points varied from 5.28 to 9.77 . Analysis of the protein domain organization showed that proteins contained the characteristic LIM domain in the conserved region. Additionally, genomic DNA sequence of the $22 \mathrm{BrLIM}$ genes was determined from the $B$. rapa chromosome sequences and the introns and exons were identified by sequence analysis. Structural information pertaining to the 22 BrLIM genes is presented in Additional file 1: Figure S1. This analysis confirmed that the identified genes code for LIM domain containing proteins. A BLAST search of the NCBI database conducted for comparison of these BrLIMs with LIM genes of other species revealed that the deduced amino acid sequences of 22 BrLIMs shared high homology, primarily with LIMs of $A$. thaliana and some other homologous species (Table 2). Pairwise amino acid sequence comparisons among these 22 BrLIM proteins were also calculated using BLAST of the NCBI database and shown in Additional file 2: Table S2. The similarity within these BrLIM protein sequences ranged from 23 to $99 \%$ and 8 BrLIMs showed above $90 \%$ similarity within the species indicating their probable duplication.

We also retrieved all LIM family protein sequences of A. thaliana, Populus trichocarpa and Oryza sativa from NCBI and constructed a phylogenetic tree with 22 
Table 1 In silico analysis of LIM genes collected from the Brassica database ${ }^{a}$

\begin{tabular}{|c|c|c|c|c|c|c|c|}
\hline \multirow{2}{*}{$\begin{array}{l}\text { Name of } \\
\text { genes }\end{array}$} & \multirow{2}{*}{$\begin{array}{c}\text { Accession } \\
\text { number }\end{array}$} & \multirow[t]{2}{*}{ ORF (bp) } & \multirow{2}{*}{$\begin{array}{c}\text { Located } \\
\text { chromosome } \\
\text { number }\end{array}$} & \multicolumn{4}{|c|}{ Protein } \\
\hline & & & & Length (aa) & $\begin{array}{l}\text { LIM domain Start - } \\
\text { end (aa) }\end{array}$ & Mol.Wt. (KD) & $\mathrm{pl}$ \\
\hline BrLIM1 & Bra014447 & 636 & A04 & 211 & 9-61 and 105-157 & 23.62 & 6.2 \\
\hline BrLIM2 & Bra007586 & 654 & A09 & 217 & 9-61 and 104-156 & 24.24 & 5.83 \\
\hline BrLIM3 & Bra033233 & 618 & $\mathrm{~A} 10$ & 205 & 9-61 and 103-155 & 22.87 & 7.12 \\
\hline BrLIM4 & Bra032650 & 618 & A09 & 205 & 9-61 and 103-155 & 22.92 & 6.77 \\
\hline BrLIM5 & Bra007189 & 606 & A09 & 201 & $10-62$ and $109-161$ & 21.88 & 9.09 \\
\hline BrLIM6 & Bra026940 & 279 & A09 & 92 & $10-62$ & 10.36 & 8.93 \\
\hline \multirow[t]{2}{*}{ BrLIM7 } & KJ686594 & 603 & $\mathrm{~A} 04$ & 200 & $10-62$ and $108-160$ & 21.88 & 9.16 \\
\hline & Bra014721 & & & & & & \\
\hline BrLIM8 & Bra005003 & 600 & A05 & 199 & 9-61 and 108-160 & 21.83 & 8.92 \\
\hline \multirow[t]{2}{*}{ BrLIM9 } & KJ686594 & 603 & $\mathrm{~A} 03$ & 200 & 9-61 and $108-160$ & 21.92 & 8.92 \\
\hline & Bra000154 & & & & & & \\
\hline BrLIM10 & Bra019956 & 573 & A06 & 190 & 9-61 and 109-161 & 21.06 & 9.11 \\
\hline BrLIM11 & Bra018454 & 570 & A05 & 189 & 9-61 and 109-161 & 20.98 & 9.02 \\
\hline BrLIM12 & Bra037160 & 1173 & A09 & 390 & $38-93$ & 44.26 & 5.68 \\
\hline BrLIM13 & Bra037159 & 1551 & A09 & 516 & 147-209 & 59.32 & 6.10 \\
\hline BrLIM14 & Bra016514 & 1389 & A08 & 462 & $102-154$ & 53.23 & 6.34 \\
\hline BrLIM15 & Bra025725 & 1584 & A06 & 527 & $166-218$ & 59.68 & 5.89 \\
\hline BrLIM16 ${ }^{d}$ & Bra011712 & 1797 & A01 & 598 & $230-282$ & 68.09 & 5.30 \\
\hline BrLIM17 & Bra005011 & 1506 & A05 & 501 & $160-224$ & 56.31 & 8.19 \\
\hline BrLIM18 & Bra000152 & 1545 & A03 & 514 & $146-198$ & 57.99 & 7.30 \\
\hline BrLIM19 & Bra012087 & 3948 & A07 & 1315 & $471-526$ & 150.61 & 5.28 \\
\hline BrLIM2O & Bra000404 & 681 & A03 & 226 & 9-61 and 103-155 & 24.93 & 6.31 \\
\hline BrLIM21 & Bra039313 & 690 & A04 & 229 & 9-61 and 105-157 & 25.13 & 6.04 \\
\hline BrLIM22 & Bra004939 & 690 & A05 & 229 & 9-61 and 105-157 & 25.03 & 6.12 \\
\hline
\end{tabular}

${ }^{\mathrm{a}}$ Brassica database (http://brassicadb.org/brad/index.php), ${ }^{\mathrm{b}}$ Genbank accession number, ${ }^{\mathrm{C}}$ Brassica database accession number, ${ }^{\mathrm{d}}$ Additional 2 UIM domain and ${ }^{\mathrm{e}}$ Additional 4 UIM domain.

deduced amino acid sequences of BrLIM using the NJ method (Figure 1, Additional file 3: Table S3). In the phylogenetic tree, previously identified LIM1 and LIM2 groups [37] were clearly separated and the plant LIM family was further divided into four groups, $\alpha$ LIM1, $\beta$ LIM1, $\gamma$ LIM2, and SLIM2, resulting from division of the LIM1 and LIM2 groups. This phylogenetic analysis confirms the existence of the PLIM1, WLIM1, PLIM2, and WLIM2 subgroups as previously described [37]. The $\alpha$ LIM1 group includes the PLIM1 and WLIM1 subgroups, while BLIM1 is a newly identified group [38]. The WLIM2 and PLIM2 subgroups belong to the $\gamma$ LIM2 and $\delta$ LIM2 groups, respectively. Among the 22 BrLIMs, BrLIM10 and 11 were clustered with WLIM1 subgroup under the $\alpha$ LIM1 group. BrLIM5, 6, 7, 8 and 9 were separated with the WLIM2 subgroup under the $\gamma$ LIM2 group. Moreover, BrLIM1, 2, 3, 4, 20, 21 and 22 separated with the PLIM2 subgroup under the $\delta$ LIM2 group, showing close relationships with the LIM sequences of other species. Multiple alignments among members of the WLIM1, WLIM2, PLIM2 and DAR groups also showed clearly distinct amino acid residues conserved in the domains and other regions of their protein sequences (Figure 2). In Arabidopsis, LIM proteins are encoded by genes from two distinct subfamilies, one encoding proteins with two LIM domains that are homologous to animal CRP proteins [37]. Consequently, highly homologous WLIM1, PLIM2, and WLIM2 proteins of $B$. rapa of this subfamily also contain two LIM domains except BrLIM6. Interestingly, with two LIM domains $\mathrm{N}$-terminal extensions were observed in BrLIM7 and 9 protein sequences and BrLIM9 had additional 11 transmembrane domains in the N-terminal extension (Figure 2, Table 1). These $\mathrm{N}$-terminal extensions suggest probable misannotation or divergent functions of these two genes which require further experimental evidence.

To investigate the existence of N-terminal extensions of BrLIM7 and 9, we analyzed expression of both genes 
Table 2 Homology analysis of LIM and DA1-related (DAR) genes of Brassica rapa ${ }^{a}$

\begin{tabular}{|c|c|c|c|c|c|c|c|}
\hline $\begin{array}{l}\text { Name of } \\
\text { genes }\end{array}$ & $\begin{array}{l}\text { New given } \\
\text { name }\end{array}$ & $\begin{array}{l}\text { Top matched } \\
\text { LIM clones }\end{array}$ & Name of proteins & Identity (\%) & E value & Homologous species & References \\
\hline \multirow[t]{2}{*}{ BrLIM1 } & BrPLIM2a & NP182104 & PLIM2a & 77 & $6 e-113$ & Arabidopsis thaliana & {$[32]$} \\
\hline & & ACB05475 & LIM protein $2 b$ & 68 & $1 e-105$ & Nicotiana tabacum & [33] \\
\hline \multirow[t]{2}{*}{ BrLIM2 } & BrPLIM2b & NP182104 & PLIM2a & 87 & $2 \mathrm{e}-112$ & A. thaliana & {$[32]$} \\
\hline & & ABK58466 & PLIM2a & 80 & $6 e-106$ & Populus tremula $\times$ Populus alba & Unpublished \\
\hline \multirow[t]{2}{*}{ BrLIM3 } & BrPLIM2C & XP002892043 & LIM protein & 95 & $7 e-144$ & Arabidopsis lyrata subsp. lyrata & Unpublished \\
\hline & & ABK58466 & PLIM2a & 74 & $2 e-99$ & P. tremula $\times$ Populus alba & Unpublished \\
\hline \multirow[t]{2}{*}{ BrLIM4 } & BrPLIM2d & NP182104 & PLIM2a & 72 & $1 e-99$ & A. thaliana & [32] \\
\hline & & XP002892043 & LIM protein & 92 & $2 \mathrm{e}-143$ & A. lyrata subsp. lyrata & Unpublished \\
\hline \multirow[t]{2}{*}{ BrLIM5 } & BrWLIM2a & ХP002879831 & LIM protein & 88 & $2 e-119$ & A. lyrata subsp. lyrata & Unpublished \\
\hline & & WLIM2a & LIM protein & 87 & $4 e-118$ & A. thaliana & [32] \\
\hline \multirow[t]{2}{*}{ BrLIM6 } & BrWLIM2b & XP002876333 & LIM protein & 91 & $8 e-52$ & A. lyrata subsp. lyrata & Unpublished \\
\hline & & AAD56951 & WLIM2 & 83 & $3 e-47$ & N. tabacum & Unpublished \\
\hline \multirow[t]{2}{*}{ BrLIM7 } & BrWLIM2C & XP002876333 & LIM protein & 93 & $3 e-122$ & A. lyrata subsp. lyrata & Unpublished \\
\hline & & ABK58469 & WLIM2a & 84 & $1 e-111$ & P. tremula $\times$ Populus alba & Unpublished \\
\hline \multirow[t]{2}{*}{ BrLIM8 } & BrWLIM2d & NP181519 & WLIM2a & 93 & $6 e-124$ & A. thaliana & {$[32]$} \\
\hline & & ACX47456 & LIM1 & 84 & $2 \mathrm{e}-113$ & Hevea brasiliensis & Unpublished \\
\hline \multirow[t]{2}{*}{ BrLIM9 } & BrWLIMZe & XP002879831 & LIM protein & 91 & $1 e-125$ & A. lyrata subsp. lyrata & Unpublished \\
\hline & & ABK58469 & WLIM2a & 81 & $4 e-114$ & P. tremula $\times$ Populus alba & Unpublished \\
\hline \multirow[t]{2}{*}{ BrLIM10 } & BrWLIM1a & NP172491 & WLIM1 & 99 & $1 e-137$ & A. thaliana & {$[34]$} \\
\hline & & ABB51614 & LIM protein & 97 & $6 e-133$ & Brassica napus & Unpublished \\
\hline \multirow[t]{2}{*}{ BrLIM11 } & BrWLIM1b & ABB51614 & LIM protein & 99 & $6 e-137$ & B. napus & Unpublished \\
\hline & & NP172491 & WLIM1 & 98 & $6 e-134$ & A. thaliana & [34] \\
\hline \multirow[t]{2}{*}{ BrLIM12 } & BrDAR1 & AED98240 & DAR6 protein & 67 & 0.0 & A. thaliana & [35] \\
\hline & & AED98241 & DAR5 protein & 64 & $5 e-160$ & A. thaliana & [35] \\
\hline \multirow[t]{2}{*}{ BrLIM13 } & BrDAR2 & AED98243 & DAR3 protein & 65 & 0.0 & A. thaliana & [35] \\
\hline & & XP003611877 & $\begin{array}{c}\text { LIM and UIM } \\
\text { domain-containing }\end{array}$ & 43 & $2 e-106$ & Medicago truncatula & Unpublished \\
\hline \multirow[t]{2}{*}{ BrLIM14 } & BrDAR3 & NP173361 & DA1 protein & 71 & 0.0 & A. thaliana & [34] \\
\hline & & EOY14670 & $\begin{array}{c}\text { LIM and UIM } \\
\text { domain-containing }\end{array}$ & 65 & 0.0 & Theobroma cacao & Unpublished \\
\hline \multirow[t]{2}{*}{ BrLIM15 } & BrDAR4 & NP173361 & DA1 protein & 87 & 0.0 & A. thaliana & [34] \\
\hline & & EOY14670 & $\begin{array}{c}\text { LIM and UIM } \\
\text { domain-containing }\end{array}$ & 66 & 0.0 & T. cacao & Unpublished \\
\hline \multirow[t]{2}{*}{ BrLIM16 } & BrDAR5 & NP195404 & DAR1 & 89 & 0.0 & A. thaliana & {$[36]$} \\
\hline & & XР003611877 & $\begin{array}{c}\text { LIM and UIM } \\
\text { domain-containing }\end{array}$ & 64 & 0.0 & M. truncatula & Unpublished \\
\hline \multirow[t]{2}{*}{ BrLIM17 } & BrDAR6 & NP181513 & DAR2 & 86 & 0.0 & A. thaliana & [32] \\
\hline & & XР003616507 & $\begin{array}{c}\text { LIM and UIM } \\
\text { domain-containing }\end{array}$ & 61 & 0.0 & M. truncatula & Unpublished \\
\hline \multirow[t]{2}{*}{ BrLIM18 } & BrDAR7 & NP181513 & DAR2 & 89 & 0.0 & A. thaliana & {$[32]$} \\
\hline & & XР003616507 & $\begin{array}{c}\text { LIM and UIM } \\
\text { domain-containing }\end{array}$ & 66 & 0.0 & M. truncatula & Unpublished \\
\hline \multirow[t]{2}{*}{ BrLIM19 } & BrDAR8 & AED98240 & DAR6 protein & 57 & $1 e-136$ & A. thaliana & [35] \\
\hline & & NP195404 & DAR1 & 42 & $2 e-51$ & A. thaliana & [36] \\
\hline \multirow[t]{2}{*}{ BrLIM2O } & BrPLIM2e & NP182104 & PLIM2a & 83 & $9 e-121$ & A. thaliana & [32] \\
\hline & & AAF75828 & PLIM2 & 70 & $2 e-84$ & N. tabacum & Unpublished \\
\hline
\end{tabular}


Table 2 Homology analysis of LIM and DA1-related (DAR) genes of Brassica rapa ${ }^{\mathrm{a}}$ (Continued)

\begin{tabular}{cccccccc}
\hline BrLIM21 & BrPLIM2f & XP002882034 & LIM protein & 86 & $1 \mathrm{e}-141$ & A. lyrata subsp. lyrata & Unpublished \\
& & NP182104 & PLIM2a & 86 & $5 \mathrm{e}-132$ & A. thaliana & [32] \\
BrLIM22 & BrPLIM2g & NP182104 & PLIM2a & 88 & $6 \mathrm{e}-133$ & A. thaliana & [32] \\
& & ABK58466 & PLIM2a & 77 & $2 \mathrm{e}-99$ & P. tremula x Populus alba Unpublished \\
\hline
\end{tabular}

${ }^{a}$ Analyzed using BLAST from NCBI, http://www.ncbi.nlm.nih.gov/BLAST/.

over different organs specifying forward and reverse primers at several locations of the sequences (Additional file 1: Figure S2). Both genes showed expression, when forward (\#5 of BrLIM7 and \#7 of BrLIM9) and reverse (\#6 of BrLIM7 and \#8 of BrLIM9) primers were selected at the conserved parts. Conversely, no expression was found, when the forward primers (\#1 of BrLIM7 and \#3 of BrLIM9) were selected at the extended parts and the reverse primers (\#3 and \#4 of BrLIM7; \#5 and \#6 BrLIM9) at several locations of the conserved parts. Subsequently, 3'-RACE PCR using primer \#1 of BrLIM7 and primer \#3 of BrLIM9 also showed discontinuation of the transcription towards conserved parts and found to show polyA tails indicating the end of the transcript. Alongside, genomic DNA amplification specifying these transition portions of both genes revealed no sequence distortion. Thus, it is clear that the extended portions are not part of BrLIM7 and 9. It was a wrong annotation of the splice sites in the original prediction. The correct exons of BrLIM7 and 9 were then drawn in the postulated gene structures (Additional file 1: Figure S2) and the primer combinations, \#5 and \#6 of BrLIM7 and \#7 and \#8 of BrLIM9 located at the corrected exons, were used in latter expression studies. These corrected sequences were deposited in the genbank under the accession numbers, KJ686594 (BrLIM7) and KJ686595 (BrLIM9). These corrected sequences are the basis for all further analysis and all figures and tables were corrected accordingly.

The genes in the second subfamily encode DA1 and DA1-related (DAR) proteins specific to plants contain a single conserved LIM domain [11]. Interestingly, BrLIM12, $13,14,15,16,17,18$ and 19 were clustered into a new group, showing close relationships with eight DA1 and DAR sequences of $A$. thaliana and four DAR sequences of $O$. sativa. Additionally, all members of this new group contain only one LIM domain, while some also contain one or more UIM(s). Therefore, BrLIM proteins were renamed according to their phylogenetic relationship as $B$. rapa DAR (BrDAR) (Table 2). Alignment of the motif sequences of the DA1 and DAR group showed very low similarity with WLIM1, WLIM2 and PLIM2 sequences, indicating their distinctness from these groups (Figure 2). However, the BrDARs were highly similar to DA1 and DAR sequences of $A$. thaliana and $O$. sativa, and these all contained similar patterns of motifs in their conserved regions. DA1 of $A$. thaliana contains two UIMs, a single
LIM domain and the highly conserved C-terminal region [11]. In contrast, DAR2 contains a single LIM domain and a putative zinc-binding domain but lacks UIMs compared with DA1 and DAR1 [30]. Similarly, BrDAR4 and 5 contain two UIMs and a single LIM domain, while BrDAR8 contains four UIM and a single LIM domain with highly conserved $\mathrm{C}$-terminal region in their protein sequences. Other BrDARs contain only a single LIM domain and highly conserved C-terminal regions (Table 1). Thus, the BrLIM genes showed high similarity with corresponding groups of LIM genes of different species, indicating their close evolutionary relationship.

\section{Organ specific expression analysis under unstressed condition}

Expression analysis was performed using specific primers with equal amounts of cDNA templates prepared from the mRNA of roots, stems, leaves and flower buds of healthy Chinese cabbage plants without applying any stresses by RT-PCR and organ specific expression was observed. Specifically, BrPLIM2d, BrWLIM2a, $b, c, d, e$, BrWLIM1 $a$ and $b$ showed expression in all the organs tested. BrPLIM2a, $b, c, B r P L I M 2 e, f$ and $g$ were only expressed in flower buds (Figure 3A). Expression of the genes that were only expressed in flower buds was further analyzed during six developmental stages (from the very young bud stage to the mature bud stage), and all genes except BrPLIM2e showed higher expression in young buds (Figure 3B). This expression pattern and phylogenetic classification revealed two clear groups of BrLIM genes, with one group (BrPLIMs except BrPLIM2d) only being expressed in flower buds and another group (WLIM) being expressed in all vegetative parts of the Chinese cabbage plants tested in this study. Thus, organ specific expressions of BrLIMs showed clear correlations with phylogenetic grouping as well.

DAR subfamily genes of B. rapa showed a different expression pattern compared to other LIM domain containing genes. Specifically, BrDAR3, 4 and 5 showed expression in all the organs tested. $\operatorname{BrDAR2}, 7$ and 8 showed expression in all organs except roots, while $\operatorname{BrDAR} 1$ was only expressed in flower buds. Noticeably, all $B r D A R$ genes expressed highly in flower buds compared to other organs (Figure 3A). Expression of BrDAR1 that was only expressed in flower buds was further analyzed during six developmental stages (from the very 


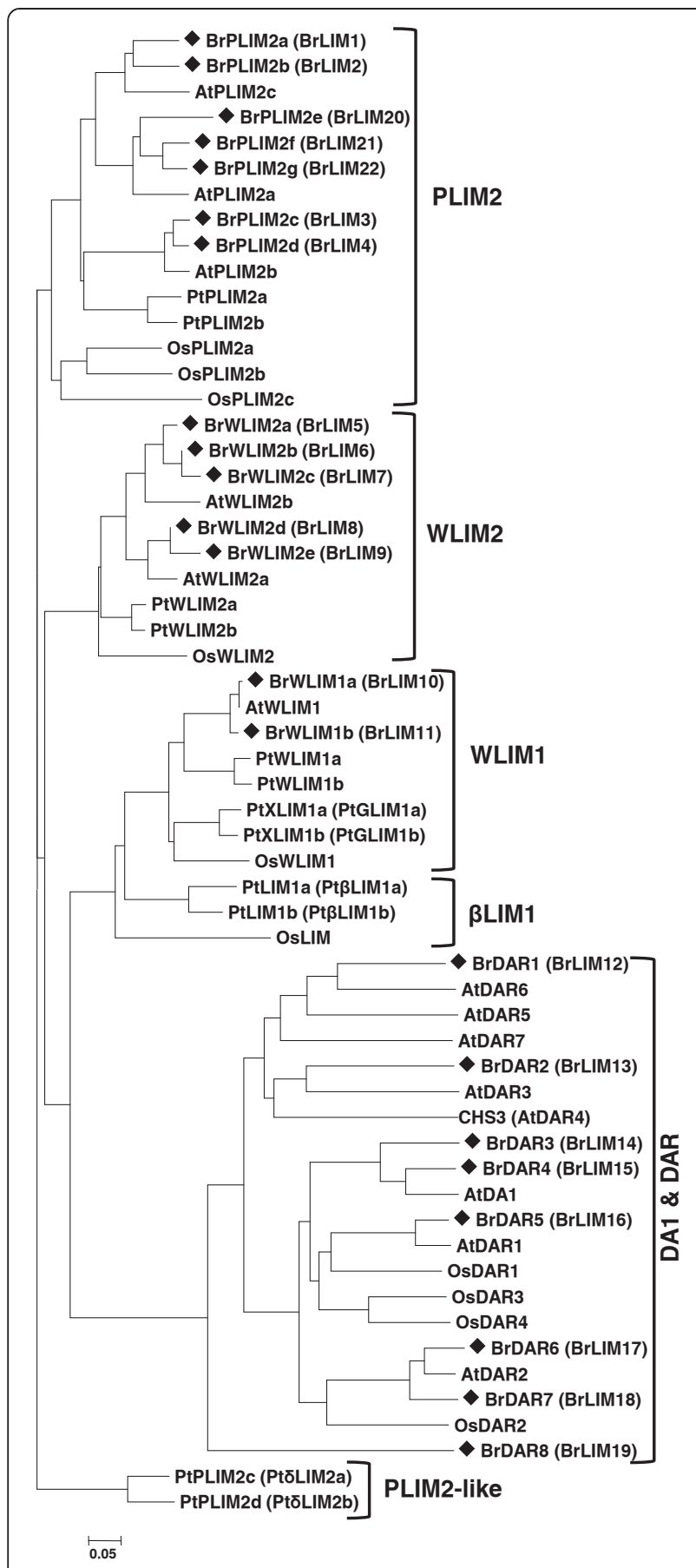

Figure 1 Phylogenetic tree showing the relatedness of the deduced full-length amino acid sequences of 22 BrLIM proteins and all LIM family proteins of $A$. thaliana, Populus trichocarpa and Oryza sativa. BrLIM proteins are indicated by square bullets. The scale represents the frequency of amino acid substitutions between sequences as determined by the Poisson evolutionary distance method. A species acronym is added before each LIM protein name: At, A. thaliana; Pt, Populus trichocarpa and Os, Oryza sativa. The old nomenclature of LIM genes are indicated under bracket. Details of each gene are given in Additional file 3: Table S3. young bud stage to the mature bud stage), and found higher expressions in young and middle aged buds (Figure 3B). Microarray expression of $D A 1$ and $D A R$ genes of $A$. thaliana were also lower at different vegetative parts compared to floral organs and comparatively higher at young flower bud stages (Figure 3 C).

The PLIM-1 protein of sunflower appeared in the microspore stage in a limited number of cytoplasmic bodies, became undetectable in bicellular pollen, and reappeared in tricellular pollen grains in cortical patches, being particularly concentrated in the F-actin-enriched germination cones of the vegetative cell. Taken together, these findings suggest a dual function of PLIM-1 gene during pollen development [39]. Conversely, expression of NtPLIM1 of tobacco in germinating pollen suggests a possible role in pollen germination and/or pollen tube growth [40]. LiLIM1, an effective actin bundling protein, also plays an important role in pollen tube growth of Lilium longiflorum [28]. Likewise, the BrPLIMs expressed in young flower bud stage might play a role in the development of pollen tube. Earlier studies have also suggested the existence of two main LIM gene subfamilies that differ in their expression patterns [37]. Again, based on phylogenetic analysis of 149 LIMs and comparison of the available expression data, a complex classification of LIM genes has been proposed by Arnaud et al., [38]. According to this classification, the Arabidopsis LIM gene family comprises three vegetative (WLIM1 and WLIM2a and $b$ ) and three reproductive (PLIM2a-c) isoforms, of which, all PLIMs have been shown to be expressed in pollen [41,42]. Ye et al. [42] also suggested the critical roles of Arabidopsis PLIMs in actin configuration during pollen germination and tube growth. Specific control of PLIM actin regulatory activities by $\mathrm{pH}$ is particularly relevant with regard to the potential biological functions of these proteins in growing tip region of pollen tubes [29].

\section{Expression analysis under stress conditions Biotic stress}

Biotic stress responses are a crucial issue for the Brassica crops and functions of LIM genes in biotic stress responses are not well studied yet. We investigated the responses of the 22 BrLIM genes identified in this study to infection by $F$. oxysporum f.sp. conglutinans in Chinese cabbage after various times. BrWLIM2c and BrDAR4 were found to be up-regulated with the time course of infection. Specifically, BrDAR4 showed very high responses in the late stages of fungal infection, while BrWLIM2c responded during earlier stages (Figure 4). AtWLIM1, AtWLIM2b, AtDAR7, AtDAR4 and AtDAR1 genes also showed responses during microarray expression analysis after infection with $F$. oxysporum in $A$. thaliana, which were collected from public database 


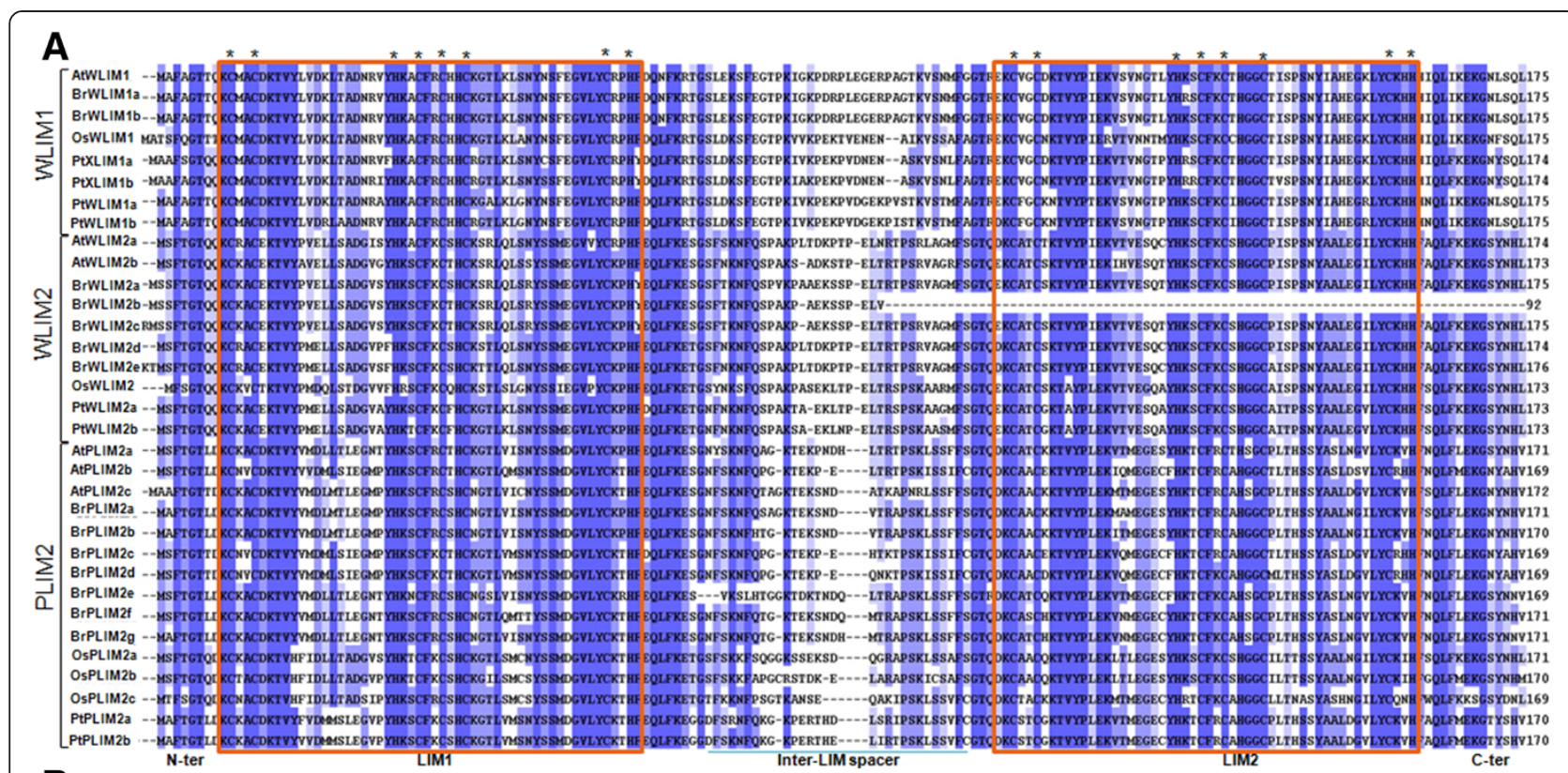

B Inter-LIM spacer

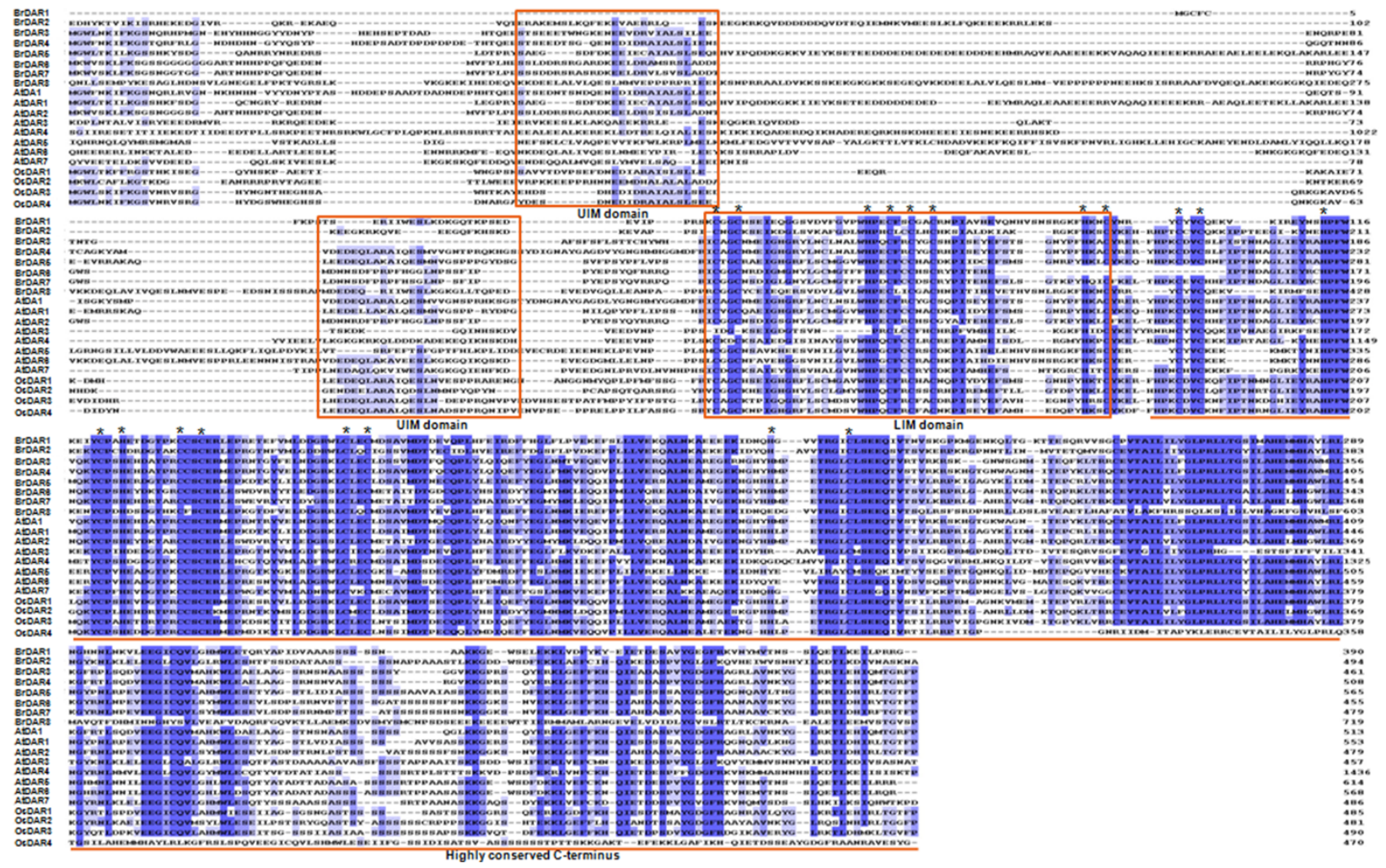

Figure 2 Alignment of deduced amino acid sequences of A) LIM and B) DAR protein groups using PIR. Solid boxes indicate UIM and LIM domains. Underline indicates highly conserved C-terminus. Asterisks show conserved cysteine and histidine residues (zinc-binding motifs) in the highly conserved LIM domains and C-terminus. Numbers in the right margin indicate the positions of amino acid residues. Identical amino acids are indicated by a dark background, while $>50 \%$ similarities are indicated by a light background.

(Additional file 4: Figure S3). We also analyzed the expression of all BrLIMs after infection with the soft rot disease causing necrotroph bacteria, Pectobacterium carotovorum subsp. carotovorum; however, no differential expression was observed in Chinese cabbage plants (data not shown). These results suggest probable involvement of BrWLIM2c and BrDAR4 with F. oxysporum f.sp. conglutinans resistance and other BrLIM and BrDAR 


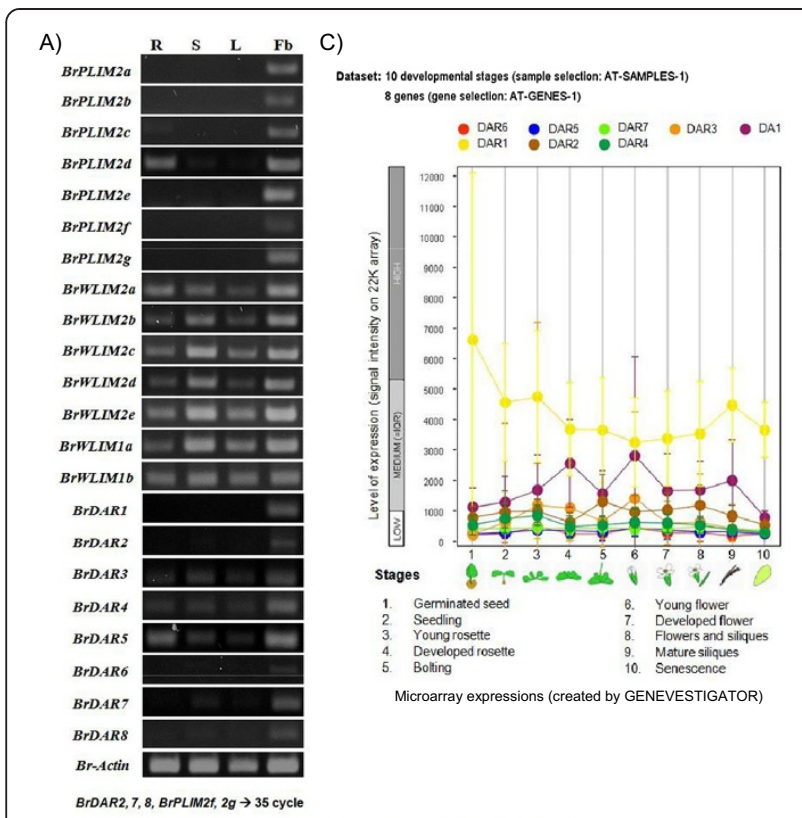

B)

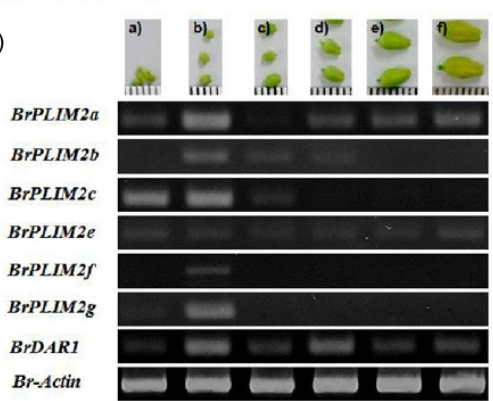

Figure 3 Expression analysis of 14 BrLIM and 8 BrDAR genes, A) over different organs, B) at six growth stages (a-f) of flower buds of Brassica rapa 'SUN-3061' plants and C) microarray expressions of $D A 1$ and seven $D A R$ genes of Arabidopsis thaliana at 10 developmental stages. Lanes $1-4$, PCR products of roots $(R)$, stems $(S)$, leaves $(L)$ and flower buds $(F b)$. a-f, young to mature stages of flower buds.

genes might also have association with resistance against other biotic stress agents in Brassica crops.

Plants encounter and must deal with a range of other organisms that may be potential partners or pathogens, and the plant cytoskeleton plays a key role in their response to such organisms. Cell wall appositions, or papillae, are important barriers formed by plants in defense against attempted penetration by fungal and oomycete pathogens [43]. Prior to the development of papillae, plant cytosol and subcellular components are rapidly translocated to the site of pathogen penetration via a mechanism known as cytoplasmic aggregation that is dependent on the action of the actin component of the cytoskeleton $[44,45]$. This cytoplasmic aggregation has been observed in many plant-microbe interactions [46] and is a common resistance response to pathogens by both dicotyledonous and monocotyledonous plants to
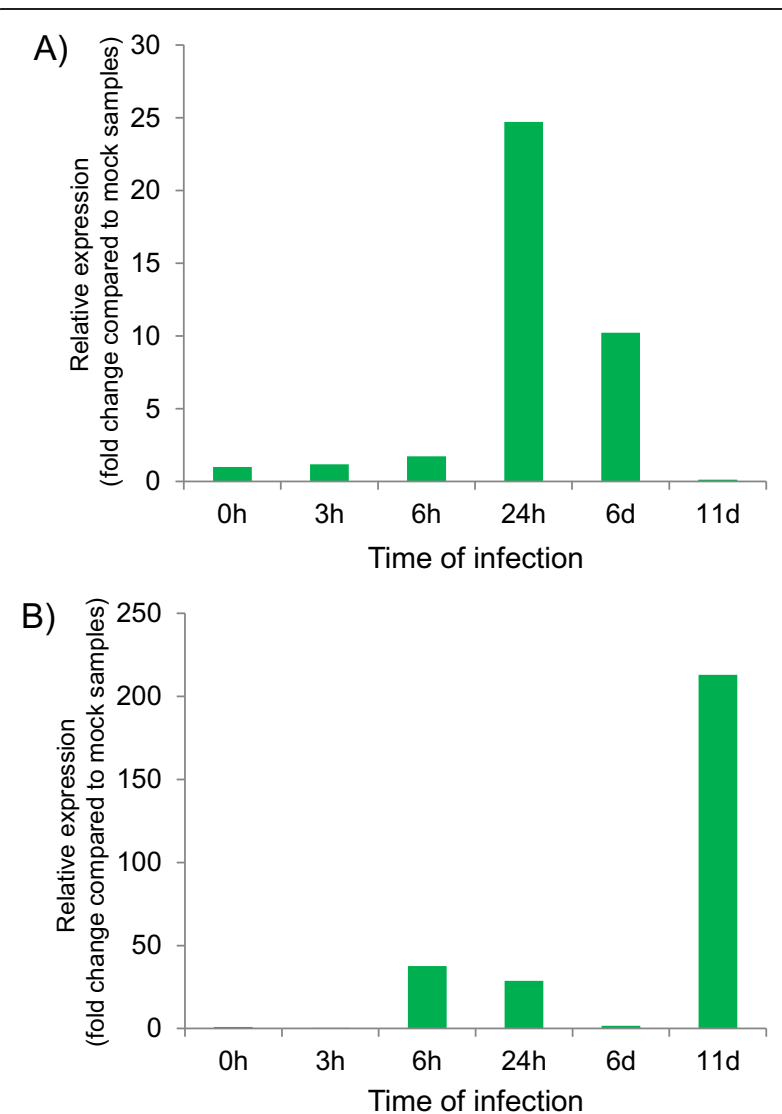

Figure 4 Real-time quantitative PCR expression analysis of A) BrWLIM2c and B) BrDAR4 after infection of Chinese cabbage (Brassica rapa 'SUN-3061') with Fusarium oxysporum f. sp. Conglutinans. Relative gene expressions in treated samples are presented as fold change compared to mock treated samples. At each time point gene expression values in mock treated samples are set to 1 .

invading filamentous pathogens. Microfilaments are the main cytoskeletal element responsible for penetration resistance based on cytoplasmic aggregation and papilla formation at the site of infection. For example, focusing of actin microfilaments at the penetration site is more extensive in resistant plants than susceptible hosts in flax (Linum usitatissimum)-Melampsora and barley (Hordeum vulgare)-Erysiphe interactions [47,48], suggesting that accumulation of material at the site of infection is related to the degree of host resistance. Some other previous observations suggest that inhibition of penetration through cytoplasmic aggregation and papilla formation is an early, if not the first, tactic in plant resistance, and that it may be backed up by the hypersensitive response [49]. Thus, the physical and chemical barrier resulting from actin-dependent cytoplasmic aggregation, secretion, and papilla formation appears to constitute an important and probably ancient form of basal resistance to pathogen attack [14]. For a full 
understanding of the cytoskeletal basis of cytoplasmic aggregation, it is very essential to elucidate the role of responsible regulatory proteins that participate in other forms of cytoplasmic streaming, as well as additional factors specific for the localized defense response. Proteins those generate intracellular motility (e.g., myosin) are likely to be important components of such regulations [19]. In addition, several CRP-like plant LIM proteins have been shown to function as ABPs [25-28], and LiLIM1 has been proposed as an effective ABP, that plays an important role in pollen tube growth of $L$. longiflorum [28]. In vitro, tobacco ( $N$. tabacum) WLIM1 binds directly to AFs and triggers the formation of thick actin bundles. Importantly, overexpression of WLIM1 proteins was sufficient to significantly increase the bundling of AFs in tobacco cells [13,27]. Thus, actin binding and bundling function of LIM genes could also be an important factor for actin-dependent resistance mechanism against pathogen infection. In this study, high expression of BrWLIM $2 c$ gene against pathogen infection is tempting to speculate that BrLIM protein may also be implicated in the perception of pathogen resistance mechanism.

Genes in the second subfamily encode DA1 proteins, which are specific to plants. The Arabidopsis LIM domain protein DA1 was characterized to function as an ubiquitin receptor [11]. Ubiquitin is a highly conserved and wide-spread small protein modifier that is engaged in a wide range of cellular [50] and biological processes, such as resistance to disease and abiotic stresses [51-53]. The consequences of ubiquitination are accusing the target protein to proteolysis or relocalization or endocytosis [54]. DA1 is inevitably involved in ubiquitination resulting extension of the cellular proliferation period, thus increasing cell numbers and ultimately plant organ size $[11,12]$. Our highly expressed BrDAR4 in response to pathogen infection might be involved in biotic stress resistance of B. rapa following aforesaid mechanism. Another member of this family CHS3/AtDAR4 containing TIR-NBS-LRR domain is associated with resistance signaling and cold response [31] and AtDAR2 with controlling of root meristem size [30]. Alongside, no BrDAR protein contained TIR-NBS-LRR domain like as CHS3/ AtDAR4. However, reports on the responses of LIM genes to biotic stresses are still lacking, and this is the first report of such possible role of LIM domain containing genes against biotic stress caused by $F$. oxysporum $\mathrm{f}$. sp. conglutinans in Chinese cabbage. Thus, BrLIM and $\operatorname{BrDAR}$ genes might be involved in biotic stress resistance related functions in $B$. rapa.

\section{Abiotic stresses}

In addition to biotic stresses, expression of BrLIMs was also analyzed in response to abiotic stress conditions such as cold, ABA and $\mathrm{pH}$ stresses. Commonly ten BrLIMs among them, showed differential expressions in response to the abiotic stresses applied in this study. Specifically, BrPLIM2d, BrWLIM2a, b, c, d, e, BrWLIM1 $a, b$, $B r D A R 3$ and 4 showed differential expression after cold, $\mathrm{ABA}$ and $\mathrm{pH}$ stress treatments compared to mock treated samples (control) of Chinese cabbage (Figure 5). BrPLIM2d, BrWLIM2a, $b$ and BrDAR4 were downregulated in response to cold stress throughout the treatment period, while BrWLIM2c, $d, e, B r W L I M 1 a, b$ and $\operatorname{BrDAR} 3$ were up-regulated during the first $8 \mathrm{~h}$ of treatment, after which they were down-regulated. Following ABA stress treatments, BrPLIM $2 d, B r W L I M 2 b, e$ and $B r D A R 4$ were also down-regulated throughout the treatment period, while BrWLIM $2 a, c, d, B r W L I M 1 a, b$ and $\operatorname{BrDAR} 3$ were up-regulated during the first $8 \mathrm{~h}$ of treatment, after which they were down-regulated. Moreover, BrPLIM2d, BrWLIM2a and BrDAR4 were down-regulated and BrWLIM1 $a, b$ BrWLIM $2 b$ and c were up-regulated throughout the treatment period in response to $\mathrm{pH} 5,7$

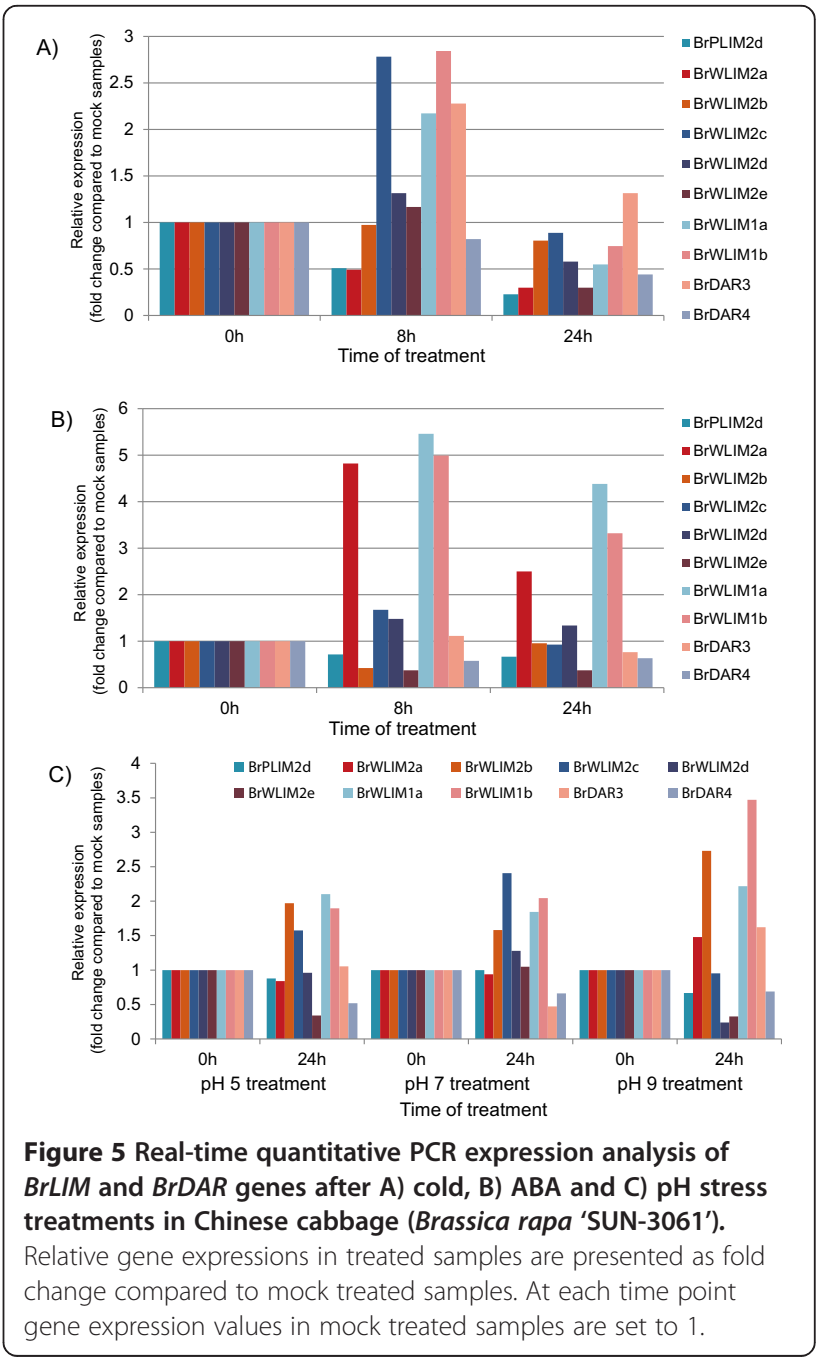


and 9 stress treatments compared to mock treated samples (control) which were maintained after transferring into a fresh medium with $\mathrm{pH}$ 5.8. BrWLIM2d and $B r W L I M 2 e$ were down-regulated in response to $\mathrm{pH} 5$ and 9, while was up-regulated in response to $\mathrm{pH}$ 7. $\mathrm{BrDAR} 3$ was down-regulated in response to $\mathrm{pH} 7$ and up-regulated in response to $\mathrm{pH} 5$ and 9. Interestingly, BrPLIM2d and BrDAR4 were down-regulated and BrWLIM1 $a, b$ and $B r W L I M 2 c$ were up-regulated in response to all abiotic stress treatments applied in this study. AtWLIM1, AtWLIM2a, AtWLIM2b, DAR7, DAR4, DAR2 and DAR1 genes also showed responses after cold stress treatments in $A$. thaliana during microarray expressions study collected from public database (Additional file 4: Figure S4).

Plants actin cytoskeleton is a major signaling target and in response to numerous abiotic and biotic stimuli, it changes dramatically in various ways, ranging from filament bundling, to massive actin depolymerization, to assembly of new filament arrays [55-57]. Plant cells can detect mechanical stress on the epidermal cell surface and respond by reorganizing subcellular components like, actin microfilaments, endoplasmic reticulum (ER) and peroxisomes in a manner similar to that induced during attack by potential fungal or oomycete pathogens [58]. Expression analysis of poplar LIMs in tension wood also suggested a connection between plant LIMs and mechanical stress [59]. Thus, rearrangement of cytoskeletal elements through actin binding and bundling may also be the mechanism of abiotic stress responses of the CRP-like LIM genes. Alongside, aforementioned ubiquitination mechanism of $D A 1$ and related proteins might also be implicated in abiotic stress resistance function of BrDAR proteins. In a very recent study, expression of GmaDA1 gene of soybeans (Glycine max) showed responses to salt, drought, acid and alkali stresses and ABA treatment [60]. AtDA1 expression occurs in response to ABA trteatment [11] and CHS3/AtDAR4 is associated with resistance signaling and cold response in A. thaliana [31]. Supporting this report Bi et al. [61] hypothesized that disease resistance and environmental stress response pathways are intricately tied in plants, although the degree of overlap and the precise signaling events required for each pathway remain unclear. Thus, the results of this study indicate the likely involvement of the analyzed genes towards abiotic stress tolerance in Brassica.

\section{Conclusion}

This present study identified 22 LIM domain containing genes in B. rapa and classified into two distinct functional groups. One group is plant-specific and designated as BrDAR, and another is CRP-like designated as BrLIM. These sequences were analyzed, compared them with LIM domain containing genes of other plants and analyzed their expression after applying biotic and abiotic stresses in Chinese cabbage. Overall, BrPLIM2d, BrWLIM2a, b, $c, d, e, B r W L I M 1 a, b, B r D A R 3$ and 4 responded after cold, $\mathrm{ABA}$ and $\mathrm{pH}$ stress treatments in B. rapa, of which BrWLIM $2 c$ and BrDAR4 showed responses to $F$. oxysporum f.sp. conglutinans infection as well. Thus, these eight BrLIMs and two BrDARs might be promising candidates for multiple abiotic stresses resistance, while $B r W L I M 2 c$ and BrDAR4 might be the most promising among them for both biotic and abiotic stresses resistance in Brassica crops. The remaining BrLIMs and BrDARs might also be useful resources for induction of resistance to other biotic and abiotic stresses and/or various developmental processes of Brassica.

\section{Methods}

\section{Plant materials}

Brassica rapa morphotype Chinese cabbage cv. SUN-3061 plants were grown at the Department of Horticulture, Sunchon National University, Korea. Fresh roots, stems, leaves and flower buds of the Chinese cabbage plants were harvested by freezing them in liquid nitrogen and stored at $-80^{\circ} \mathrm{C}$ to carry out subsequent organ specific expression studies.

\section{Stress treatments}

Chinese cabbage plants were infected with $F$. oxysporum f.sp. conglutinans at the Screening Center for Disease Resistant Vegetable Crops, Korea. A modified version of the root-dip inoculation (RDI) method was used to inoculate the Chinese cabbage with the fungus [62]. Briefly, three week old seedlings were removed from the soil and immersed in the conidial suspension. Samples were then collected from infected and mock-infected plants at $0 \mathrm{~h}, 3 \mathrm{~h}, 6 \mathrm{~h}, 24 \mathrm{~h}, 6 \mathrm{~d}$ and $11 \mathrm{~d}$. Upon collection, the samples were immediately frozen in liquid nitrogen, after which they were stored at $-80^{\circ} \mathrm{C}$ until RNA isolation. The local (fourth) and systemic (fifth) leaves were harvested as samples.

For biotic stress treatments, Chinese cabbage plants were grown in soil for six weeks under culture room conditions with a $16 \mathrm{~h}$ light $8 \mathrm{~h}$ dark cycle at $25^{\circ} \mathrm{C}$ temperature prior to treatment. $P$. carotovorum subsp. carotovorum stock $(10 \mu \mathrm{l})$ was cultured in $25 \mathrm{ml}$ of liquid YEP medium until the $\mathrm{OD}_{600}$ was 1.4 , which was equivalent to $1,170,000$ colony forming units $(\mathrm{cfu}) \mathrm{ml}^{-1}$, after which it was diluted to an $\mathrm{OD}_{600}$ of 1.19 , which was equal to $1 \times 10^{6} \mathrm{CFU} \mathrm{ml}^{-1}$, by adding double distilled water. For pathogen inoculation, $10 \mu \mathrm{l}$ of $P$. carotovorum subsp. carotovorum culture solution $\left(1 \times 10^{6} \mathrm{cfu} \mathrm{ml}^{-1}\right)$ was added to a freshly needle wounded site at the lower $1 / 3$ of the midrib of the upper third leaves, after which the sample was covered with polyvinyl bags to maintain $80-90 \%$ humidity and incubated at $25^{\circ} \mathrm{C}$. All inoculations 
were performed three times, and the infection was confirmed by observing disease lesions in the leaves of the Chinese cabbage plants. Approximately one-third of the top of the infected leaves were harvested for RNA extraction at $0 \mathrm{~h}, 6 \mathrm{~h}, 12 \mathrm{~h}, 24 \mathrm{~h}$, and $72 \mathrm{~h}$ after inoculation, frozen in liquid nitrogen, and stored at $-80^{\circ} \mathrm{C}$.

For abiotic stress treatments, Chinese cabbage seeds were grown aseptically on half-strength MS (HMS) agar medium (without sucrose) with $\mathrm{pH}$ of 5.8 in a culture room under a $16 \mathrm{~h}$ light photoperiod at $25^{\circ} \mathrm{C}$. After three weeks of growth, the seedlings were transferred to fresh liquid HMS medium containing $100 \mu \mathrm{M}$ of $\mathrm{ABA}$ for ABA stress treatments. To induce cold stress, the seedlings were maintained at $4^{\circ} \mathrm{C}$ in fresh liquid HMS medium for $24 \mathrm{~h}$. In addition, $\mathrm{pH}$ stress treatment was applied by transferring the seedlings into fresh liquid HMS medium with $\mathrm{pH}$ levels of 5,7 or 9 for $24 \mathrm{~h}$. For each stress, the leaf samples were collected after $0 \mathrm{~h}, 8 \mathrm{~h}$ and $24 \mathrm{~h}$ of treatment and each sample was collected three times from two plants every time. Mock treated samples (control) were collected from the seedlings after transferring into same fresh liquid HMS medium with $\mathrm{pH}$ levels of 5.8 during same time interval. The collected samples were frozen immediately in liquid nitrogen and stored at $-80^{\circ} \mathrm{C}$ until RNA isolation.

\section{RNA extraction}

Total RNA was extracted from the roots, stems, leaves, flower buds of six different stages (early to mature flower bud) and stress treated frozen samples using an RNeasy mini kit (Qiagen, USA), after which it was treated with RNase-free DNase (Promega, USA) to remove genomic DNA contaminants.

\section{Sequence analysis of $B r L I M$ genes}

We recovered 22 LIM genes of B. rapa from the Brassica database (http://brassicadb.org/brad/index.php) using the key word "LIM protein". The primary structure of genes was then analyzed using protParam (http://expasy.org/ tools/protparam.html). Exons were drawn using gene structure display server 2.0 (http://gsds2.cbi.pku.edu.cn/) and open reading frames (ORFs) were determined using ORF finder (http://www.ncbi.nlm.nih.gov/gorf/gorf.html). Additionally, an alignment search was conducted using NCBI BLAST (http://www.ncbi.nlm.nih.gov/BLAST/) and the BLASTp program with the $\mathrm{nr}$ database. Typical domains were analyzed using the EMBL web tool (http:// smart.embl.de/smart/set_mode.cgi?GENOMIC=1). Multiple protein sequences were aligned using PIR (http://pir. georgetown.edu/pirwww/search/multialn.shtml) and phylogenetic tree was constructed according to the neighborjoining method using the MEGA5.1 software (http://www. megasoftware.net) $[63,64]$.

\section{Expression analysis RT-PCR analysis}

AMV one step RT-PCR kit (Takara, Japan) was used for RT-PCR. Specific primers for all genes were used for RT-PCR, and actin primers of B. rapa (FJ969844) were used as a control (Additional file 2: Table S1). We used primer 3 program for designing primers and Tm values for forward and reverse primers of each gene was determined at $55 \pm 1^{\circ} \mathrm{C}$. PCR was performed using $50 \mathrm{ng}$ of cDNA from the roots, leaves, stems and flower buds as templates in master mixes composed of 20 pmol of each primer, $150 \mu \mathrm{M}$ of each dNTP, 1.2 U of Taq polymerase, $1 \times \mathrm{Taq}$ polymerase buffer, and double-distilled $\mathrm{H}_{2} \mathrm{O}$ diluted to a total volume of $20 \mu \mathrm{l}$ in $0.5 \mathrm{ml}$ PCR tubes. The samples were then subjected to the following conditions: pre-denaturing at $94^{\circ} \mathrm{C}$ for $5 \mathrm{~min}$, followed by 30 cycles of denaturation at $94^{\circ} \mathrm{C}$ for $30 \mathrm{~s}$, annealing at $55^{\circ} \mathrm{C}$ for $30 \mathrm{~s}$ and extension at $72^{\circ} \mathrm{C}$ for $1 \mathrm{~min}$, with a final extension for $5 \mathrm{~min}$ at $72^{\circ} \mathrm{C}$. Microarray expression of $A$. thaliana genes were created by GENEVESTIGATOR (https://www.genevestigator.com/gv/plant.jsp).

\section{3'-RACE PCR}

The cDNA synthesized from $B$. rapa sample was reverse transcribed and the trapped sequence adjacent to the vector was amplified by 3'-RACE using a TAKARA 3'Full RACE Core set according to the manufacturer's instructions. For BrWLIM2c and e-specific PCR the primers F-1 (5'-GTG AAC ACA ACA GAG GAG GT$\left.3^{\prime}\right)$ and F-2 (5'-AGT GAG CAC AAT CCC TCT TA-3') were used for amplification of the target portions, respectively. The PCR products were then cloned using a TOPO TA 2.1 cloning kit (Invitrogen, USA) according to the manufacturer's instructions and sequenced with an ABI3700 sequencer (SolGent Co., Ltd., Korea).

\section{Real-time quantitative PCR analysis}

The cDNA was synthesized using a Superscript ${ }^{\circ}$ III First-Strand synthesis kit (Invitrogen, USA) according to the manufacturer's instructions using oligo dT primer. Real-time quantitative PCR was performed using $1 \mu \mathrm{l}$ of cDNA in a $25 \mu$ l reaction volume employing iTaq $^{\mathrm{mm}}$ SYBR $^{\circ}$ Green PCR kit (Qiagen, California, USA). The same specific primers were used for real-time PCR and actin primers of B. rapa (FJ969844) were used as a control and the conditions for real-time PCR were as follows: $10 \mathrm{~min}$ at $95^{\circ} \mathrm{C}$, followed by 40 cycles of $94^{\circ} \mathrm{C}$ for $30 \mathrm{~s}$ (denaturation), $58^{\circ} \mathrm{C}$ for $30 \mathrm{~s}$ (extension step), and $72^{\circ} \mathrm{C}$ for $45 \mathrm{~s}$ (signal aquisition). The fluorescence was measured following the last step of each cycle, and three replicates were used for each sample. Amplification, detection, and data analysis were conducted using a Rotor-Gene 6000 real-time rotary analyzer (Corbett Life Science, Australia). Threshold cycle (Ct) represents the 
number of cycles at which the fluorescence intensity was significantly higher than the background at the initial exponential phase of PCR amplification. The Br-Actin was used as the internal reference in all analyses and relative gene expression level was calculated on the basis of the $2^{-\Delta \Delta C t}$ method [65]. Finally, the relative gene expressions in treated samples were presented as fold change compared to mock treated samples and at each time point gene expression values in mock treated samples are set to 1 .

\section{Additional files}

Additional file 1: Figure S1. Gene structure of 22 LIM genes of Brassica rapa. Solid boxes and lines indicate exons and introns respectively. Length of exons and introns are mentioned below in base pairs (bps). Figure S2. Schematic representation of the existing and the postulated genomic structures of A) BrLIM7 and B) BrLIM9. Solid boxes and lines indicate exons and introns respectively and their lengths are mentioned above in base pairs (bps). Specific primers were indicated by arrows, forward $(\rightarrow)$ and reverse $(\leftarrow)$, with corresponding numbers for RT-PCR expression analysis over different organs, roots (R), stems (S), leaves (L) and flower buds (Fb), and genomic DNA amplifications, which are represented beneath each genes. Primer \#1 and \#3, indicated by green arrows $(\rightarrow)$, were used for 3'-RACE PCR of BrLIM7 and BrLIM9, respectively.

Additional file 2: Table S1. Primers specific for 22 BrLIM genes used for RT and Real time PCR analysis. Table $\mathbf{S 2}$. Sequence relatedness among 22 LIM proteins of Brassica rapa.

Additional file 3: Table S3. List of genes selected for phylogenetic analysis with sequences of deduced proteins of B. rapa.

Additional file 4: Figure $\mathbf{S 3}$. Microarray expressions of six $L I M$, one $D A 1$ and seven DAR genes of Arabidopsis thaliana after infection with Fusarium oxysporum (created by GENEVESTIGATOR). Figure S4. Microarray expressions of six LIM, one DA1 and seven DAR genes of Arabidopsis thaliana after cold stress treatments (created by GENEVESTIGATOR).

\section{Abbreviations}

LIM: Lin-11, Isl-1 and Mec-3 domains; BrLIM: Brassica rapa LIM; ABA: Abscisic acid; CRPs: Cysteine rich proteins; AFs: Actin filaments; ABPs: Actin binding proteins; kDa: Kilo Dalton; RDI: Root-dip inoculation; cfu: Colony forming units; HMS: Half-strength Murashige and Skoog; UIM: Ubiquitin interacting motif; RACE: Rapid amplification of cDNA ends.

\section{Competing interests}

The authors declare that they have no competing interests.

\section{Authors' contribution}

Conceived and designed the experiments: JP, NUA, MW, ISN. Performed the experiments: NUA, JIP, HJJ. Analyzed the data/gave suggestions: NUA, JIP, HJJ, SKTA, MYC, YGC, MW, ISN. Contributed reagents/materials/analysis tools: JIP, NUA, HJJ, SKTA, MYC, YGC, MW, ISN. Wrote the paper: NUA and JIP. All authors read and approved the final manuscript.

\section{Acknowledgements}

This research was supported by basic Science Research Program though the National Research Foundation of Korea (NRF) funded by the Ministry of Education, Science and Technology (NRF-2010-355-C00054, 2012R1A1A2044500). and Golden Seed Project (Center for Horticultural Seed Development, No. 213003-04-2-SB420), Ministry of Agriculture, Food and Rural Affairs (MAFRA), Ministry of Oceans and Fisheries (MOF), Rural Development Administration (RDA) and Korea Forest Service (KFS).

\section{Author details}

'Department of Horticulture, Sunchon National University, 255 Jungangno, Suncheon, Jeonnam 540-950, Republic of Korea. ${ }^{2}$ Department of Agricultural Education, Sunchon National University, 413 Jungangno, Suncheon, Jeonnam 540-742, Republic of Korea. ${ }^{3}$ Department of Crop Science, Chungbuk
National University, 410 Seongbongro, Heungdokgu, Cheongju 361-763, Republic of Korea. ${ }^{4}$ Laboratory of Plant Reproductive Genetics, Graduate School of Life Sciences, Tohoku University, 2-1-1, Katahira, Aoba-ku, Sendai 980-8577, Japan.

Received: 5 February 2014 Accepted: 24 July 2014 Published: 3 August 2014

\section{References}

1. Dawid IB, Toyama R, Taira M: LIM domain proteins. CR Acad Sci [III] 1995, 318:295-306.

2. Taira M, Evrard JL, Steinmetz A, Dawid IB: Classification of LIM proteins. Trends Genet 1995, 11:431-432

3. Schmeichel KL, Beckerle MC: The LIM domain is a modular proteinbinding interface. Cell 1994, 79:211-219.

4. Jurata LW, Pfaff SL, Gill GN: The nuclear LIM domain interactor NLI mediates homo- and heterodimerization of LIM domain transcription factors. J Biol Chem 1998, 273:3152-3157.

5. Freydt G, Kim SK, Horvitz HR: Novel cysteine-rich motif and homeodomain in the product of the Caenorhabditis elegans cell lineage gene lin-11. Nature 1990, 344:876-879.

6. Karlsson O, Thor S, Norberg T, Ohlsson H, Edlund T: Insulin gene enhancer binding protein Isl-1 is a member of a novel class of proteins containing both a homeo- and a Cys-His domain. Nature 1990, 344:879-882.

7. Way JC, Chalfie M: mec-3, a homeobox-containing gene that specifies differentiation of the touch receptor neurons in C. elegans. Cell 1988, 54:5-16.

8. Wadman IA, Osada H, Grutz GG, Agulnick AD, Westphal H, Forster A, Rabbitts TH: The LIM-only protein Lmo2 is a bridging molecule assembling an erythroid, DNA binding complex which includes the TAL1, E47, GATA-1 and Ldb1/NLI proteins. EMBO J 1997, 16:3145-3157.

9. Arber S, Barbayannis FA, Hanser H, Schneider C, Stanyon CA, Bernard O, Caroni P: Regulation of actin dynamics through phosphorylation of cofilin by LIM-kinase. Nature 1998, 393:805-809.

10. Yang N, Higuchi O, Ohashi K, Nagata K, Wada A, Kangawa K, Nishida E, Mizuno K: Cofilin phosphorylation by LIM-kinase 1 and its role in Racmediated actin reorganization. Nature 1998, 393:809-812.

11. Li Y, Zheng L, Corke F, Smith C, Bevan MW: Control of final seed and organ size by the DA1 gene family in Arabidopsis thaliana. Genes Dev 2008, 22:1331-1336

12. Xia T, Li N, Dumenil J, Li J, Kamenski A, Bevan MW, Gao F, Li Y: The Ubiquitin Receptor DA1 Interacts with the E3 Ubiquitin Ligase DA2 to Regulate Seed and Organ Size in Arabidopsis. Plant Cell 2013, 25(9):3347-3359.

13. Thomas C, Dieterle M, Gatti S, Hoffmann C, Moreau F, Papuga J, Steinmetz A: Actin bundling via LIM domains. Plant Signal Behav 2008, 3:320-321.

14. Thordal-Christensen $\mathrm{H}$ : Fresh insights into processes of nonhost resistance. Curr Opin Plant Biol 2003, 6:351-357.

15. Takagi S: Roles for actin filaments in chloroplast motility and anchoring. In Actin: A Dynamic Framework for Multiple Plant Cell Functions. Edited by Staiger C. Dordrecht, The Netherlands: Kluwer Academic Publishers; 2000:203-212.

16. Blancaflor EB: The cytoskeleton and gravitropism in higher plants. J Plant Growth Regul 2002, 21:120-136.

17. Foissner I, Lichtscheidl IK, Wasteneys GO: Actin-based vesicle dynamics and exocytosis during wound wall formation in characean internodal cells. Cell Motil Cytoskeleton 1996, 35:35-48.

18. Hush JM, Overall RL: Cortical microtubule reorientation in higher plants: dynamics and regulation. J Microsc 1996, 181:129-139.

19. Shimmen T, Yokota E: Cytoplasmic streaming in plants. Curr Opin Cell Biol 2004, 16:68-72.

20. Vidali L, Yokota E, Cheung AY, Shimmen T, Hepler PK: The 135 kDa actinbinding protein from Lilium longiflorum pollen is the plant homologue of villin. Protoplasma 1999, 209:283-291

21. Kovar DR, Staiger CJ, Weaver EA, McCurdy DW: AtFim1 is an actin filament crosslinking protein from Arabidopsis thaliana. Plant J 2000, 24:625-636.

22. Hepler PK, Vidali L, Cheung AY: Polarized cell growth in higher plants. Annu Rev Cell Dev Biol 2001, 17:159-187.

23. Shimmen $\mathrm{T}$ : The sliding theory of cytoplasmic streaming: Fifty years of progress. J Plant Res 2007, 120:31-43.

24. Winder SJ, Ayscough KR: Actin-binding proteins. J Cell Sci 2005, 118:651-654.

25. Grubinger M, Gimona M: CRP2 is an autonomous actinbinding protein. FEBS Lett 2004, 557:88-92. 
26. Tran TC, Singleton C, Fraley TS, Greenwood JA: Cysteine-rich protein 1 (CRP1) regulates actin filament bundling. BMC Cell Biol 2005, 6:45.

27. Thomas C, Hoffmann C, Dieterle M, Van Troys M, Ampe C, Steinmetz A: Tobacco WLIM1 is a novel F-actin binding protein involved in actin cytoskeleton remodeling. Plant Cell 2006, 18:2194-2206.

28. Wang HJ, Wan AR, Jauh GY: An actin-binding protein, LILIM1, mediates calcium and hydrogen regulation of actin dynamics in pollen tubes. Plant Physiol 2008, 147:1619-1636.

29. Papuga J, Hoffman C, Dieterle M, Moes D, Moreau F, Tholl S, Steinmetz A, Thomas C: Arabidopsis LIM proteins: a family of actin bundlers with distinct expression patterns and modes of regulation. Plant Cell 2010, 22:3034-3052.

30. Peng Y, Ma W, Chen L, Yang L, Li S, Zhao H, Zhao Y, Jin W, Li N, Bevan MW, Li X, Tong Y, Li Y: Control of Root Meristem Size by DA1-RELATED PROTEIN2 in Arabidopsis. Plant Physiol 2013, 161:1542-1556.

31. Yang H, Shi Y, Liu J, Guo L, Zhang X, Yang S: A mutant CHS3 protein with TIR- NB-LRR-LIM domains modulates growth, cell death and freezing tolerance in a temperature-dependent manner in Arabidopsis. Plant $J$ 2010, 63:283-296

32. Lin X, Kaul S, Rounsley S, Shea TP, Benito MI, Town CD, Fujii CY, Mason T, Bowman CL, Barnstead M: Sequence and analysis of chromosome 2 of the plant Arabidopsis thaliana. Nature 1999, 402(6763):761-768

33. Cheung AY, Duan QH, Costa SS, de Graaf BH, Di Stilio VS, Feijo J, Wu HM: The dynamic pollen tube cytoskeleton: live cell studies using actin-binding and microtubule-binding reporter proteins. Mol Plant 2008, 1(4):686-702.

34. Theologis A, Ecker JR, Palm CJ, Federspiel NA, Kaul S, White O, Alonso J, Altafi H, Araujo R, Bowman CL, Brooks SY, Buehler E, Chan A, Chao Q, Chen $\mathrm{H}$ : Sequence and analysis of chromosome 1 of the plant Arabidopsis thaliana. Nature 2000, 408(6814):816-820.

35. Tabata S, Kaneko T, Nakamura Y, Kotani H, Kato T, Asamizu E, Miyajima N, Sasamoto S: Sequence and analysis of chromosome 5 of the plant Arabidopsis thaliana. Nature 2000, 408(6814):823-826.

36. Mayer K, Schuller C, Wambutt R, Murphy G, Volckaert G, Pohl T, Dusterhoft A, Stiekema W, Entian KD: Sequence and analysis of chromosome 4 of the plant Arabidopsis thaliana. Nature 1999, 402(6763):769-777.

37. Eliasson A, Gass N, Mundel C, Baltz R, Kräuter R, Evrard JL, Steinmetz A: Molecular and expression analysis of a LIM protein gene family from flowering plants. Mol Gen Genet 2000, 264:257-267.

38. Arnaud D, Dejardin A, Leple JC, Lesage-Descauses MC, Pilate G: Genomewide analysis of LIM gene family in Populus trichocarpa, Arabidopsis thaliana, and Oryza sativa. DNA Res 2007, 14:103-116.

39. Baltz R, Schmit AC, Kohnen M, Hentges F, Steinmetz A: Differential localization of the LIM domain protein PLIM-1 in microspores and mature pollen grains from sunflower. Sex Plant Reprod 1999, 12:60-65.

40. Sweetman J, Spurr C, Eliasson A, Gass N, Steinmetz A, Twell D: Isolation and characterization of two pollen-specific LIM domain protein CDNAs from Nicotiana tabacum. Sex Plant Reprod 2000, 12:339-345.

41. Alves-Ferreira M, Wellmer F, Banhara A, Kumar V, Riechmann JL, Meyerowitz EM: Global expression profiling applied to the analysis of Arabidopsis stamen development. Plant Physiol 2007, 145:747-762.

42. Ye JR, Zhou LM, Xu ML: Arabidopsis LIM proteins PLIM2a and PLIM2b regulate actin configuration during pollen tube growth. Biol Plant 2013, 57(3):433-441

43. Aist JR: Papillae and related wound plugs of plant cells. Annu Rev Phytopathol 1976, 14:145-163.

44. Tomiyama K, Sato K, Doke N: Effect of cytochalasin B and colchicines on hypersensitive death of potato cells infected by incompatible race of Phytophthora infestans. Ann Phytopathol Soc Jpn 1982, 48:228-230.

45. Hazen BE, Bushnell WR: Inhibition of the hypersensitive reaction in barley to powdery mildew by heat shock and cytochalasin B. Physiol Plant Pathol 1983, 23:421-438.

46. Takemoto D, Jones DA, Hardham AR: GFP-tagging of cell components reveals the dynamics of subcellular re-organization in response to infection of Arabidopsis by oomycete pathogens. Plant J 2003, 33:775-777.

47. Kobayashi I, Kobayashi Y, Hardham AR: Dynamic reorganization of microtubules and microfilaments in flax cells during the resistance response to flax rust infection. Planta 1994, 195:237-247.

48. Kobayashi I, Kobayashi $Y$, Yamaoka N, Kunoh H: Recognition of a pathogen and a nonpathogen by barley coleoptile cells. III. Responses of microtubules and actin filaments in barley coleoptile cells to penetration attempts. Can J Bot 1992, 70:1815-1823.
49. Collins NC, Thordal-Christensen H, Lipka V, Bau S, Kombrink E, Qiu JL, Huckelhoven R, Stein M, Freialdenhoven A, Somerville SC, Schulze-Lefert P: SNARE-protein-mediated disease resistance at the plant cell wall. Nature 2003, 425:973-977.

50. Vierstra RD: The ubiquitin-26S proteasome system at the nexus of plant biology. Nat Rev Mol Cell Biol 2009, 10:385-397.

51. Dreher K, Callis J: Ubiquitin, hormones and biotic stress in plants. Ann Bot 2007, 99:787-822

52. Trujillo M, Shirasu K: Ubiquitination in plant immunity. Curr Opin Plant Biol 2010, 13:402-408

53. Liu YC, Wu YR, Huang XH, Sun J, Xie Q: AtPUB19, a U-box E3 ubiquitin ligase, negatively regulates abscisic acid and drought responses in Arabidopsis thaliana. Mol Plant 2011, 4(6):938-946.

54. Ikeda F, Dikic I: A typical ubiquitin chains: new molecular signals, 'Protein modifications: Beyond the Usual Suspects' review series. EMBO Rep 2008, 9:536-542

55. Smertenko A, Franklin-Tong VE: Organisation and regulation of the cytoskeleton in plant programmed cell death. Cell Death Differ 2011, 18:1263-1270.

56. Higaki T, Kurusu T, Hasezawa S, Kuchitsu K: Dynamic intracellular reorganization of cytoskeletons and the vacuole in defense responses and hypersensitive cell death in plants. J Plant Res 2011, 124:315-324.

57. Day B, Henty JL, Porter KJ, Staiger CJ: The pathogen-actin connection: A platform for defense signaling in plants. Annu Rev Phytopath 2011 49:489-506

58. Hardham AR, Takemoto D, White RG: Rapid and dynamic subcellular reorganization following mechanical stimulation of Arabidopsis epidermal cells mimics responses to fungal and oomycete attack. BMC Plant Biol 2008, 8:63

59. Arnaud D, Dejardin A, Leple JC, Lesage-Descauses MC, Boizot N, Villar M, Benedetti $\mathrm{H}$, Pilate G: Expression analysis of LIM gene family in poplar, toward an updated phylogenetic classification. BMC Res Notes 2012, 5:102

60. Zhao M, He L, Gu Y, Wang Y, Chen Q, He C: Genome-wide analyses of a plant-specific LIM-domain gene family implicate its evolutionary role in plant diversification. Genome Biol Evol 2014, 6(4):1000-1012.

61. Bi D, Johnson KCM, Zhu Z, Huang Y, Chen F, Zhang Y, Li X: Mutations in an atypical TIR-NB-LRR-LIM resistance protein confer autoimmunity. Front Plant Sci 2011, 2:71.

62. Ospina-Giraldo MD, Mullins E, Kang S: Loss of function of the Fusarium oxysporum SNF1 gene reduces virulence on cabbage and Arabidopsis. Curr Genet 2003, 44:49-57.

63. Saitou N, Nei M: The neighbor-joining method: a new method for reconstructing phylogenetic trees. Mol Biol Evol 1987, 4:406-425

64. Tamura K, Dudley J, Nei M, Kumar S: MEGA4: Molecular evolutionary genetics analysis (MEGA) software version 5.1. Mol Biol Evol 2007, 24:1596-1599.

65. Livak KJ, Schmittgen TD: Analysis of relative gene expression data using real-time quantitative PCR and the $2^{-\Delta \Delta C t}$ method. Methods 2001 25:402-408

doi:10.1186/1471-2164-15-641

Cite this article as: Park et al:: Identification and characterization of LIM gene family in Brassica rapa. BMC Genomics 2014 15:641.

\section{Submit your next manuscript to BioMed Central and take full advantage of:}

- Convenient online submission

- Thorough peer review

- No space constraints or color figure charges

- Immediate publication on acceptance

- Inclusion in PubMed, CAS, Scopus and Google Scholar

- Research which is freely available for redistribution 